Journal of Advanced College of Engineering and Management, Vol. 5, 2019

\title{
CRASH PREDICTION FOR PRIORITIZATION OF INTERSECTIONS FOR SAFETY IMPROVEMENT: CASE STUDY OF KATHMANDU VALLEY
}

\author{
Suraj Bhattarai ${ }^{1}$ \\ ${ }^{1}$ Lecturer/DHoD, Department of Civil Engineering, Advanced College of Engineering and Management
}

\begin{abstract}
Every year globally 1.3 million people lose their lives from road traffic crashes (RTAs). Similarly, increasing rate of RTAs has been observed in Nepal including Kathmandu valley. This study is focused on the analysis of crash trends and respective site specific geometric features of urban road intersections in Kathmandu valley. Seventeen major intersections based on the data availability and traffic volume, are considered for the analysis of crash type. Previous crash data and traffic volume records of one year have been analysed. Common types of three and four legged intersections were taken for the study. Classified traffic volume at those intersections were converted into the Annual Average Daily Traffic. Evaluation factors for the crash analysis were determined by using predictive method. Crash frequency, crash rate, critical crash rate and crash prediction methods were used for ranking of the intersection. Priority for the safety improvement is prepared based on the results of this study.
\end{abstract}

Keywords: Crashes; Intersections; Ranking; Predictive Methods; Prioritization; Safety Improvement

\section{Background}

Overall development of the country depends on the transport infrastructure and efficient transport service. In fact, road infrastructure is one of the indicator of a nation to be developed. Therefore the infrastructure of road network in a country should be efficient and adequate. The facilities in the road network should be such that the mobility of transport and people should be safe and reliable. "Each year nearly 1.3 million people die as a result of a road traffic collision - more than 3000 deaths each day - and more than half of these people are not travelling in a car. Twenty to fifty million more people sustain non-fatal injuries from a collision, and these injuries are an important cause of disability worldwide" (United Nation, 2011). Ninety percent of road traffic deaths occur in low- and middle-income countries, which claim less than half the world's registered vehicle fleet. Road traffic injuries are among the three leading causes of death for people between 5 and 44 years of age. Unless immediate and effective action is taken, road traffic injuries are predicted to become the fifth leading cause of death in the world, resulting in an estimated 2.4 million deaths each year (United Nation, 2011). This is, in part, a result of rapid increases in motorization without sufficient improvement in road safety strategies and land use planning. The economic consequences of motor vehicle crashes have been estimated between $1 \%$ and $3 \%$ of the respective Gross National Product (GNP) of the world countries, reaching a total over $\$ 500$ billion. Reducing road casualties and fatalities will reduce suffering, unlock growth and free resources for more productive use. Intersection crashes are one of the major issues in Kathmandu valley road networks. Even the small crashes may create large congestion and blockage of traffic flow during peak hours or even beyond. The number of crashes occurring in major intersections are increasing yearly (MTPO, 2016). The number of crashes at major intersections are recorded and it shows that total of 3621 crashes occurred at intersection in the year 2013. It increased to 3915 in the year 2014 and to 4330 in 2015.

\section{Literature Review}

The statistics on road crashes globally suggests that over 1.17 million people die in road crashes. There are $65 \%$ of deaths involving pedestrians $35 \%$ among them are children. More than 10 million get incapacitated annually (Mehar \& Agrawal, 2013). It is expected that road crashes will be the fifth major cause of death in the year 2030(World Health Organization, 2013). Intersection-related crashes 
are associated with high proportion of crashes involving drivers, occupants, pedestrians, and cyclists. A significant portion of total fatal crashes usually occur at intersections. In order to enhance the safety of intersections, significant attention is needed to ensure safe movement of road users. Many researchers have come out with the causes, effects and recommendations to vehicular crashes in Ghana and elsewhere. For instance, Ayeboo (2009), identified that the numerous crashes on our road networks have been linked to various causes which include over speeding, drink driving, wrong over taking, poor road network and the rickety vehicles which ply on our roads. Furthermore, Thapa (2013) has identified many causes of road crashes in Nepal which include unnecessary speeding, lack of proper judgment of drivers, inadequate experience, carelessness, wrong overtaking, recklessness, over loading, dazzling and defective light, unwillingness to alight from motion objects (vehicles, motor cycles, human being and uncontrolled animals), skid and road surface defect, level crossing and obstruction. Other factors are inadequate enforcement of road laws and traffic regulations, use of mobile phones when driving, failure to buckle the seat belt and corruption (Thapa, 2013).

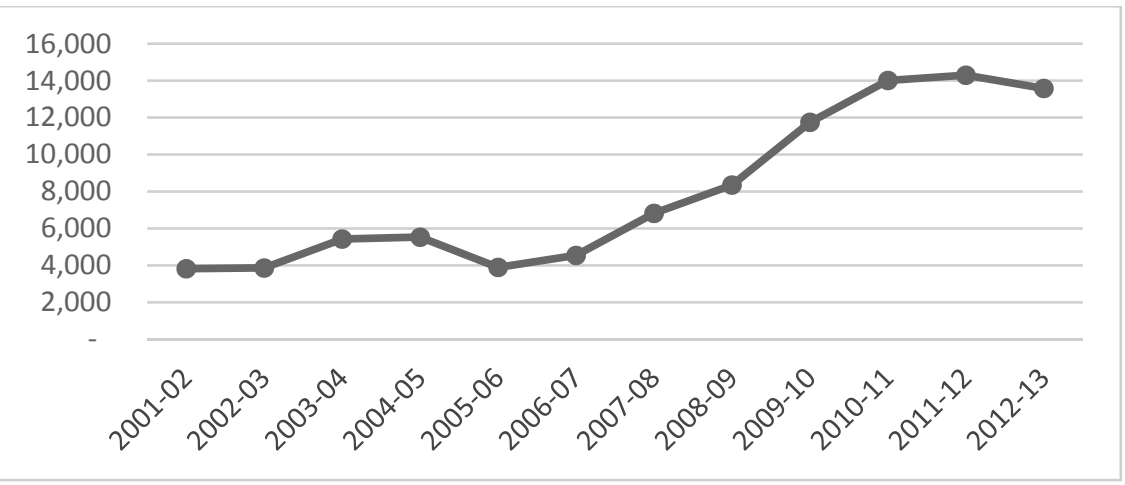

Fig1: Road Accident Trends in Nepal

Source: Status Paper on Road Safety in Nepal, (Thapa, 2013)

The rate of fatality are also in increasing trend from 2013/14 and crossed 2000 in 2014/15 as shown in figure 2 .

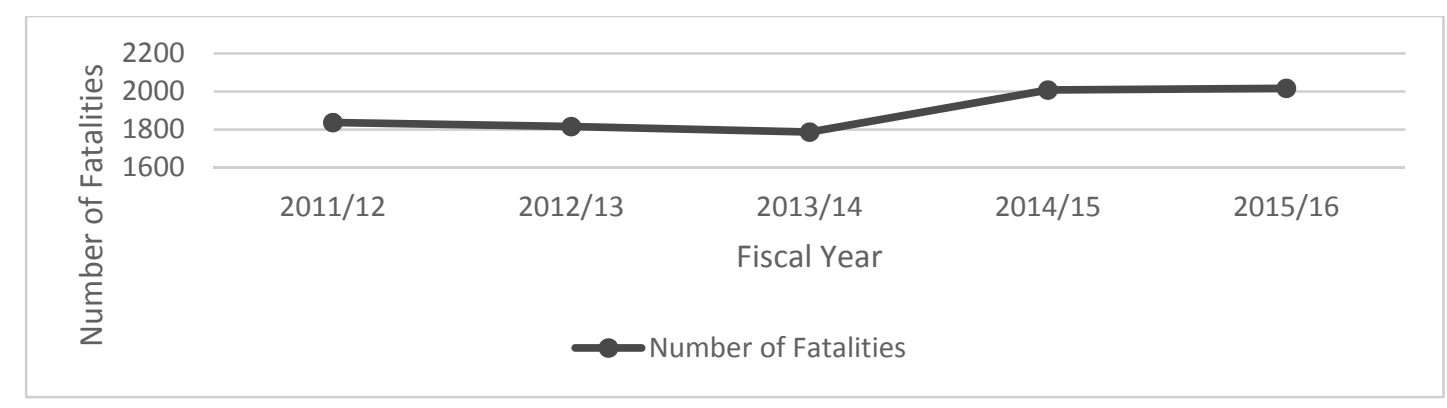

Fig 2: Trend of Fatalities in Road Crashes

Source: MTPO (2016)

\section{Challenges in Crash Reduction}

To reduce the crash on road intersections channelization is one of the most effective measures. It provides positive guidance to the driver and as the result simplifies the movements and reduces the room for error, reduces confusion, separates and localizes the conflict points. According to HSM (AASTHO, 2009), at intersections, each of these elements presents challenges: 
* Control: The path through the intersection is typically unmarked and may involve turning

* Guidance: There are numerous potential conflicts with other vehicles, pedestrians, and cyclists on conflicting paths and

* Navigation: Changes in direction are usually made at intersections, and road name signing can be difficult to locate and read in time to accomplish any required lane changes.

In the process of negotiating any intersection, drivers are required to:

* Detect the intersection

* Identify signalization and appropriate paths; Search for vehicles, pedestrians, and bicyclists on a conflicting path;

* Assess adequacy of gaps for turning movements;

* Rapidly make a stop/go decision on the approach to a signalized intersection when in the decision zone; and,

* Successfully complete through or turning manoeuvres.

\section{Predictive model in Highway Safety Manual}

The highway safety manual provides safety performance functions (SPF) for the intersections and roadways divided into rural two lane two-way roads, rural multilane highways and urban and suburban arterials. The SPFs provide the predicted total crash frequency for base condition and for the effect of individual geometric design and traffic control features. Basic elements of accident predictive models of HSM (AASTHO, 2009) are listed as follows:

\section{Safety Performance Functions (SPFs)}

Safety Performance Functions (SPFs) are regression equations that estimate the average crash frequency for a specific site type (with specified base conditions) as a function of annual average daily traffic (AADT) and, in the case of roadway segments, the segment length (L). Base conditions are specified for each SPF and may include conditions such as lane width, presence or absence of lighting, presence of turn lanes etc.

\section{Accident Modification Factors (AMFs)}

Accident Modification Factors (AMFs) represent the relative change in crash frequency due to a change in one specific condition (when all other conditions and site characteristics remain constant). AMFs are the ratio of the crash frequency of a site under two different conditions

\section{Calibration Factor (C)}

Calibration factor $(\mathrm{C})$ is multiplied with the crash frequency predicted by the SPF to account for differences between the jurisdiction and time period for which the predictive models were developed and the jurisdiction and time period to which they are applied by HSM users. While the functional form of the SPFs varies in the HSM, the predictive model to estimate the expected average crash frequency.

\section{Data Collection and Analysis}

The study was conducted firstly collecting the required data. The data was then analyzed and ranking of intersection was performed. On the basis of the results, priority for intersection safety countermeasures were recommended for top ranked intersection. For the collection of primary data, all the intersection were visited and the facilities available at each intersections were taken. Other primary data were taken through an interview with the traffic police officers for the purpose of nature of accident patterns, precise locations of accident, causes of accident and possible remedies for the 
intersections. After the collection of data it was analysed using Microsoft Excel and interpretation of data are done with the help of tabulated values and descriptive methods. Firstly the road accident data were analysed and ranking of the intersection according to the number of crashes. Then the crash frequency method was used for analysing the rank of intersection based on crash frequency with the help of traffic volume data. After that the prediction of crashes were done and intersections were ranked. For the secondary data the traffic accident records were taken from the Metropolitan Traffic Police Office (MTPO) at Singhadurbar as data for all the intersections were available centrally for the study period of 2013 to 2016.

\subsection{Average Crash Frequency}

The site with the most total crashes or the most crashes of a particular crash severity or type, in a given time period, is given the highest rank. Applying the Crash Frequency performance measure produces a simple ranking of sites according to total crashes or crashes by type and/or severity. This method can be used to select an initial group of sites with high crash frequency for further analysis.

\subsection{Crash Rate}

The crash rate performance measure normalizes the frequency of crashes with the exposure, measured by traffic volume. When calculating a crash rate traffic volumes are reported as million entering vehicles (MEV) per intersection for the study period. The exposure on roadway segments is often measured per million. Crash rate performance measure normalizes the number of crashes relative to exposure (traffic volume) by dividing the total number of crashes by the traffic volume.

\subsection{Critical Crash Rate}

The observed crash rate at each site is compared to a calculated critical crash rate that is unique to each site. The critical crash rate is a threshold value that allows for a relative comparison among sites with similar characteristics. Sites that exceed their respective critical rate are flagged for further review. Critical crash rate for each intersection can be calculated from following equation (Highway Safety Manual, 2009).

$$
R_{c}=R_{a}+\left[P x \sqrt{\frac{R_{a}}{M E V i}}+\frac{1}{2(M E V i)}\right]
$$

$\mathrm{R}_{\mathrm{c}}=\quad$ Critical Crash Rate

$\mathrm{R}_{\mathrm{a}}=\quad$ Average Crash Rate

$\mathrm{P}=\quad$ constant related to level of statistical significance selected (1.96 used for this study) (AASTHO, 2009)

$\mathrm{MEV}_{\mathrm{i}}=$ Million entering vehicle for the particular intersection. 
Table 1: Input data Requirement for the Accident Prediction Model for Intersection

\begin{tabular}{|c|c|}
\hline Input Data & Base Condition \\
\hline Intersection type (3ST, 4ST, 4SG) & - \\
\hline $\mathrm{AADT}_{\text {major }}$ (veh/day) & - \\
\hline $\mathrm{AADT}_{\text {minor }}(\mathrm{veh} /$ day $)$ & - \\
\hline Intersection Skew Angle (Degrees) & 0 \\
\hline $\begin{array}{l}\text { Number of signalized or uncontrolled approaches with a } \\
\text { left turn lane }(0,1,2,3,4)\end{array}$ & 0 \\
\hline $\begin{array}{l}\text { Number of signalized or uncontrolled approaches } \\
\text { with a right turn lane }(0,1,2,3,4)\end{array}$ & 0 \\
\hline Intersection lighting (present/not present) & Not Present \\
\hline Calibration Factor, $\mathrm{C}_{\mathrm{i}}$ & 1 \\
\hline
\end{tabular}

3ST- $\quad$ Unsignalised three-legged intersection with minor road stop control

4ST- $\quad$ Unsignalised four-legged intersection with minor road stop control

4SG- $\quad$ Signalised four-legged intersection

$\mathrm{AADT}_{\text {major- }} \quad$ Average Annual Daily Traffic of Major Leg

$\mathrm{AADT}_{\text {minor- }} \quad$ Average Annual Daily Traffic of Minor Leg

The predictive method gives the estimate of total average crash frequency of the particular intersection. As per HSM (AASTHO, 2009) the model used for this study is:

Npredictedint $=\mathrm{N}_{\text {spfint }} \times \mathrm{C}_{\mathrm{i}} \times($ AMF $1 \mathrm{i} \times$ AMF $2 \mathrm{i} \times \ldots \times$ AMF 6i $)$

Where,

Npredictedint $=\quad$ predicted average crash frequency for an individual intersection for the selected year;

Nspfint $=\quad$ predicted average crash frequency for an intersection with base conditions;

AMF $1 i \ldots$ AMF6 $i=$ Accident Modification Factors for intersections;

$\mathrm{C} i=$ calibration factor for intersections of a specific type developed for use for a particular jurisdiction or geographical area.

Nspfint $=\mathrm{N}_{\text {bimv }}+\mathrm{N}_{\text {bisv }}$

$\mathrm{N}_{\text {bimv }}=$ Predicted average number of multiple-vehicle collisions for base conditions

$\mathrm{N}_{\text {bisv }}=$ Predicted average number of single-vehicle collisions for base conditions

The effects of geometric design or traffic control features are incorporated through the Accident Modification Factor (AMF). The AMF for base condition of each geometric design or traffic control features has a value of 1.0 and features with higher crash frequency has AMF value greater than 1.0 
whereas features with lower crash frequency has AMF value less than 1.0. AMFs considered for this study is enlisted as follows:

$\begin{array}{lll}* \text { AMF1i- } & \text { Intersection Left Turn Lanes } \\ \text { * AMF2i- } & \text { Intersection Right Turn Signal Phasing } \\ \text { * AMF3i- } & \text { Intersection Right Turn Lanes } \\ \text { * AMF4i- } & \text { Right Turn on Red } \\ \text { * AMF5i- } & \text { Intersection Lighting } \\ * \text { AMF6i- } & \text { Red Light Cameras }\end{array}$

Appropriate countermeasure were selected on the basis of ranking prioritization and guidelines provided by National Cooperation Highway Research Program (NCHRP, 2003)shown in Table 2.

Table 2: Matrix for Countermeasures at Intersection

\begin{tabular}{|c|c|c|c|c|c|}
\hline $\begin{array}{l}\text { Traffic } \\
\text { Control } \\
\text { System }\end{array}$ & $\begin{array}{l}\text { Intersection } \\
\text { Marking }\end{array}$ & $\begin{array}{l}\text { Pedestrian } \\
\text { Crossings }\end{array}$ & Geometry & Enforcement & Education \\
\hline $\begin{array}{l}\text { Signalized } \\
\text { Unsignalized } \\
\text { Traffic Signs } \\
\text { Condition of } \\
\text { Traffic } \\
\text { control } \\
\text { devices } \\
\text { Traffic } \\
\text { Volume }\end{array}$ & $\begin{array}{l}\text { Right Turn } \\
\text { Lanes } \\
\text { Left Turn } \\
\text { Lanes } \\
\text { Stop Marks } \\
\text { Marking of } \\
\text { Pedestrian } \\
\text { Crossing }\end{array}$ & $\begin{array}{l}\text { Type of } \\
\text { crossing } \\
\text { facility } \\
\text { Availability } \\
\text { of space for } \\
\text { improving } \\
\text { structures }\end{array}$ & $\begin{array}{l}\text { Intersection } \\
\text { Geometry } \\
\text { Sight } \\
\text { Distance }\end{array}$ & $\begin{array}{l}\text { Traffic rule } \\
\text { enforcements }\end{array}$ & $\begin{array}{l}\text { Awareness } \\
\text { among road } \\
\text { users } \\
\text { Drivers } \\
\text { education }\end{array}$ \\
\hline
\end{tabular}

\section{Findings}

The crashes records according to (MTPO, 2016), has records of 34 locations out of which seventeen major intersections along Kathmandu valley are taken on the basis of their traffic volume. The intersections considered for the ranking purpose of the study are taken after the study was made on the accident record data and the ones with available data for all the study period are considered. However, according to (MTPO, 2016) the records of the crashes presented in the data are not of the intersections only but comprises of the locations along which the traffic police office is located, its surroundings and its duty areas. The actual number of crashes at the intersection itself ranges from $20-25 \%$ of the total accident as stated by traffic police during interview, and thus $20 \%$ of the total crashes are considered for the prediction of crashes in the intersection. The number of accident around the facility does not affect the ranking by average crash frequency and crash rate methods.

\section{Average Crash Frequency}

Applying the crash frequency performance measure produces a simple ranking of sites according to total crashes or crashes by type or severity. This method can be used to select an initial group of sites with high crash frequency for further analysis (Highway Safety Manual, 2009). For this analysis a crash data by location is essential. Firstly the name of intersections were arranged in alphabetical order and identification number (Intersection ID) was given. Figure 3 shows the total number of 
crashes at all the intersections for the three years showing that Koteshwor intersection has exceptional number of accident. Other intersection does however shows the similar number of crashes.

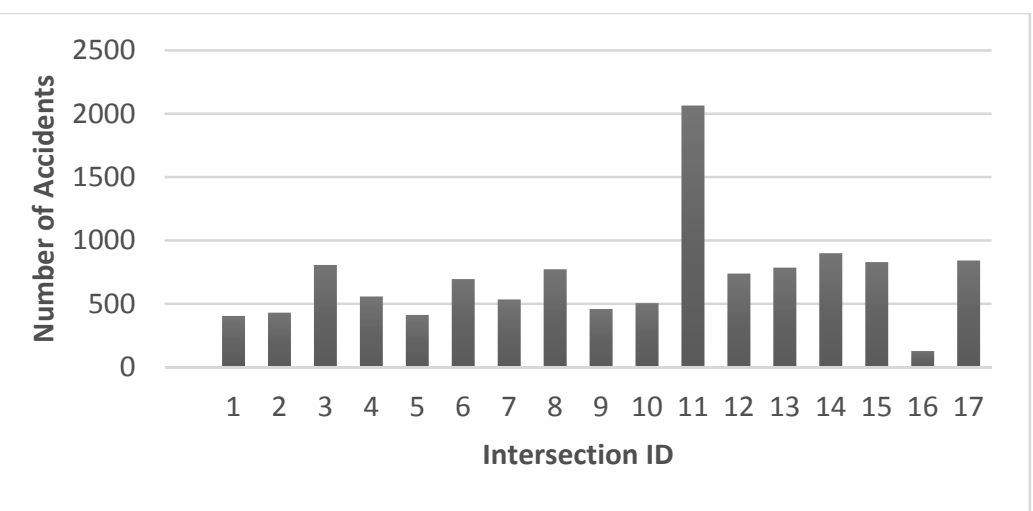

Fig 3: Total Number of Accident

With total accident records studied for the study year 2013/2014 to 2015/2016 the intersection were ranked according to the crash frequency at and around the location. Table 3shows the ranking of intersections for average crash frequency.

Table 3: Ranking of Intersection by Average Crash Freuency

\begin{tabular}{|c|c|c|c|c|c|c|c|}
\hline Rank & $\begin{array}{l}\text { Interse } \\
\text { ction } \\
\text { ID }\end{array}$ & Intersection Name & $\begin{array}{l}2013 / \\
2014\end{array}$ & $\begin{array}{l}2014 / \\
2015\end{array}$ & $\begin{array}{l}2015 / \\
2016\end{array}$ & Total & $\begin{array}{l}\text { Crashes at } \\
\text { Intersections }\end{array}$ \\
\hline 1 & 11 & Koteshwor & 597 & 674 & 795 & 2066 & 413 \\
\hline 2 & 14 & Singhadurbar & 342 & 377 & 181 & 900 & 180 \\
\hline 3 & 17 & Thimi & 280 & 227 & 335 & 842 & 168 \\
\hline 4 & 15 & Swyambhu & 210 & 283 & 336 & 829 & 166 \\
\hline 5 & 3 & Buspark & 284 & 327 & 196 & 807 & 161 \\
\hline 6 & 13 & Satdobato & 319 & 214 & 253 & 786 & 157 \\
\hline 7 & 8 & Kalanki & 194 & 243 & 336 & 773 & 155 \\
\hline 8 & 12 & Narayangopalchok & 207 & 291 & 241 & 739 & 148 \\
\hline 9 & 6 & Gaushala & 162 & 178 & 355 & 695 & 139 \\
\hline 10 & 4 & Chabahil & 195 & 195 & 168 & 558 & 112 \\
\hline 11 & 7 & Jawalakhel & 203 & 146 & 185 & 534 & 107 \\
\hline 12 & 10 & Kamalpokhari & 122 & 194 & 189 & 505 & 101 \\
\hline 13 & 9 & Kalimati & 125 & 147 & 187 & 459 & 92 \\
\hline 14 & 2 & Balkhu & 138 & 133 & 159 & 430 & 86 \\
\hline 15 & 5 & Durbarmarg & 67 & 128 & 217 & 412 & 82 \\
\hline 16 & 1 & Airport & 145 & 133 & 126 & 404 & 81 \\
\hline 17 & 16 & Thapathali & 31 & 25 & 71 & 127 & 25 \\
\hline
\end{tabular}




\section{Crash Rate}

Crash rate of all the intersections were calculated as:

$$
\begin{gathered}
M E V=\left(\frac{T E V}{1,000,000}\right) X(n) X(365) \\
R=\frac{N_{\text {observed (Total) }}}{M E V}
\end{gathered}
$$

$\mathrm{R}=\quad$ Observed Crash rate at intersection

$\mathrm{N}_{\text {observed (Total) }}=$ Total Observed crashes at intersection

$\mathrm{MEV}_{\mathrm{i}}=\quad$ Million entering vehicle at intersection

The crash rate of each intersections were calculated and the Table 4 shows the ranking of intersections on the basis of the crash rates at the intersection.

\begin{tabular}{|c|c|c|c|c|c|c|c|}
\hline $\begin{array}{l}\text { Ranki } \\
\text { ng }\end{array}$ & $\begin{array}{l}\text { Intersec } \\
\text { tion ID }\end{array}$ & $\begin{array}{l}\text { Intersection } \\
\text { Name }\end{array}$ & $\begin{array}{l}\text { Total } \\
\text { Crashes }\end{array}$ & $\begin{array}{l}\text { Accident at } \\
\text { Intersection }\end{array}$ & $\begin{array}{l}\text { Traffic Volume } \\
\text { (AADT) }\end{array}$ & Exposure & $\begin{array}{l}\text { Crash } \\
\text { Rate }\end{array}$ \\
\hline 1 & 11 & Koteshwor & 2066 & 413 & 22,353 & 24.48 & 16.8733 \\
\hline 2 & 14 & Singhadurbar & 900 & 180 & 13,673 & 14.97 & 12.0225 \\
\hline 3 & 10 & Kamalpokhari & 505 & 101 & 7,762 & 8.50 & 11.8832 \\
\hline 4 & 7 & Jawalakhel & 534 & 107 & 9,124 & 9.99 & 10.7099 \\
\hline 5 & 2 & Balkhu & 430 & 86 & 8,678 & 9.50 & 9.05034 \\
\hline 6 & 17 & Thimi & 842 & 168 & 18,250 & 19.98 & 8.40683 \\
\hline 7 & 8 & Kalanki & 773 & 155 & 18,070 & 19.79 & 7.83356 \\
\hline 8 & 3 & Buspark & 807 & 161 & 19,263 & 21.09 & 7.63287 \\
\hline 9 & 15 & Swyambhu & 829 & 166 & 20,244 & 22.17 & 7.48855 \\
\hline 10 & 13 & Satdobato & 786 & 157 & 19,557 & 21.41 & 7.33134 \\
\hline 11 & 9 & Kalimati & 459 & 92 & 11,646 & 12.75 & 7.21435 \\
\hline 12 & 4 & Chabahil & 558 & 112 & 17,346 & 18.99 & 5.89664 \\
\hline 13 & 5 & Durbarmarg & 412 & 82 & 13,432 & 14.71 & 5.57518 \\
\hline 14 & 12 & $\begin{array}{l}\text { Narayangopalch } \\
\text { ok }\end{array}$ & 739 & 148 & 26,982 & 29.55 & 5.00926 \\
\hline 15 & 6 & Gaushala & 695 & 139 & 25,619 & 28.05 & 4.95494 \\
\hline 16 & 1 & Airport & 404 & 81 & 28,735 & 31.46 & 2.5743 \\
\hline 17 & 16 & Thapathali & 127 & 25 & 12,142 & 13.30 & 1.88034 \\
\hline
\end{tabular}

Table 4: Ranking of Intersection by Crash Rate 


\section{Critical Crash Rate}

The observed crash rate at each site is compared to a calculated critical crash rate that is unique to each site. The critical crash rate is a threshold value that allows for a relative comparison among sites with similar characteristics. Sites that exceed their respective critical rate are flagged for further review. The critical crash rate depends on the average crash rate at similar sites, traffic volume, and a statistical constant that represents a desired level of significance.

$$
R_{c}=R_{a}+\left[P x \sqrt{\frac{R_{a}}{M E V i}}+\frac{1}{2(M E V i)}\right]
$$

$\mathrm{R}_{\mathrm{c}}=\quad$ Critical Crash Rate

$\mathrm{R}_{\mathrm{a}}=\quad$ Average Crash Rate

$\mathrm{P}=\quad$ constant related to level of statistical significance selected (1.96 used for this study)

(AASTHO, 2009)

$\mathrm{MEV}_{\mathrm{i}}=$ Million entering vehicle for the intersection

Similarly the critical rate of all the intersection were calculated and presented in the Table 5 and highlighted intersections are the one flagged for further study.

Table 5: Ranking of Intersections by Critical Crash Rates

\begin{tabular}{|c|c|c|c|c|c|c|c|c|}
\hline $\begin{array}{l}\text { Ranki } \\
\text { ng }\end{array}$ & $\begin{array}{l}\text { Intersect } \\
\text { ion ID }\end{array}$ & $\begin{array}{l}\text { Intersection } \\
\text { Name }\end{array}$ & $\begin{array}{l}\text { Accident } \\
\text { at Intersection }\end{array}$ & $\begin{array}{l}\text { Traffic } \\
\text { Volume } \\
\text { (AADT) }\end{array}$ & MEV & $\begin{array}{l}\text { Crash } \\
\text { Rate }\end{array}$ & $\begin{array}{l}\text { Average } \\
\text { Crash }\left(\mathbf{R}_{\mathrm{a}}\right)\end{array}$ & $\begin{array}{l}\text { Critical } \\
\text { Crash } \\
\text { Rate }\left(\mathbf{R}_{\mathbf{c}}\right)\end{array}$ \\
\hline 1 & 10 & Kamalpokhari & 101 & 7,762 & 8.50 & 11.883 & 7.785 & 8.801 \\
\hline 2 & 2 & Balkhu & 86 & 8,678 & 9.50 & 9.050 & 7.785 & 8.743 \\
\hline 3 & 7 & Jawalakhel & 107 & 9,124 & 9.99 & 10.710 & 7.785 & 8.718 \\
\hline 4 & 9 & Kalimati & 92 & 11,646 & 12.75 & 7.214 & 7.785 & 8.606 \\
\hline 5 & 16 & Thapathali & 25 & 12,142 & 13.30 & 1.880 & 7.785 & 8.588 \\
\hline 6 & 5 & Durbarmarg & 82 & 13,432 & 14.71 & 5.575 & 7.785 & 8.547 \\
\hline 7 & 14 & Singhadurbar & 180 & 13,673 & 14.97 & 12.022 & 7.785 & 8.539 \\
\hline 8 & 4 & Chabahil & 112 & 17,346 & 18.99 & 5.897 & 7.785 & 8.452 \\
\hline 9 & 8 & Kalanki & 155 & 18,070 & 19.79 & 7.834 & 7.785 & 8.438 \\
\hline 10 & 17 & Thimi & 168 & 18,250 & 19.98 & 8.407 & 7.785 & 8.434 \\
\hline 11 & 3 & Buspark & 161 & 19,263 & 21.09 & 7.633 & 7.785 & 8.416 \\
\hline 12 & 13 & Satdobato & 157 & 19,557 & 21.41 & 7.331 & 7.785 & 8.411 \\
\hline 13 & 15 & Swyambhu & 166 & 20,244 & 22.17 & 7.489 & 7.785 & 8.400 \\
\hline 14 & 11 & Koteshwor & 413 & 22,353 & 24.48 & 16.873 & 7.785 & 8.369 \\
\hline 15 & 6 & Gaushala & 139 & 25,619 & 28.05 & 4.955 & 7.785 & 8.330 \\
\hline 16 & 12 & $\begin{array}{l}\text { Narayangopalcho } \\
\mathrm{k}\end{array}$ & 148 & 26,982 & 29.55 & 5.009 & 7.785 & 8.315 \\
\hline 17 & 1 & Airport & 81 & 28,735 & 31.46 & 2.574 & 7.785 & 8.298 \\
\hline
\end{tabular}




\section{Crash Prediction for Intersections}

For the prediction of crashes in intersections firstly the facility type of intersections are categorized. The intersections are categorized as three-leg unsignalized intersection (3ST) and four legunsignalized intersection (4ST). Separate calibration coefficient are calculated for each facility type. The SPFs for each of the four intersection types identified above predict total crash frequency per year for crashes that occur within the limits of the intersection. The SPFs and adjustment factors address the following four types of collisions.
* Multiple-vehicle collisions
* Single-vehicle crashes
* Vehicle-pedestrian collisions
* Vehicle-bicycle collisions

The regression coefficients for multiple vehicle collision for intersection are adopted from HSM.

\section{Accident Modification Factors for Intersections}

The effects of individual geometric design and traffic control features of intersections are represented in the predictive models by AMFs. AMF1 $i$ through AMF $4 i$ are applied to multiple-vehicle collisions and single-vehicle crashes at intersections, but not to vehicle-pedestrian and vehicle-bicycle collisions.

\section{Predicted average crash frequency for Shinghadurbar Intersection}

$\mathrm{N}_{\text {predictedint }}=\quad 0.946$ for calibration coefficient is considered 1 as per HSM (AASTHO, 2009).

For the crash prediction of the 3ST intersections for the study year 2015/2016 the calibration coefficient is calculated and calibrated as per the HSM (AASTHO, 2009).

For the calibration of 3ST intersection firstly the determination of calibration coefficient is carried out, which can be calculated as:

$$
C i=\frac{\text { Eobserved Crashes }}{\text { DPredicted Crashes }} \quad C i=\frac{396}{9.572}=41.371
$$

The calculated calibration coefficient is greater than 1 , thus the intersections used to calculate the coefficient has more crashes than the facility type used for development of SPF on an average.

After applying the calibration coefficient the prediction of crashes for the study year 2015/2016 is done and ranked in descending order as shown in Table 6 for 3ST intersection facilities.

Table 6: Ranking of Three Legged Unsignalized Intersection

\begin{tabular}{|c|c|c|}
\hline Intersection ID & Intersection Name & Predicted Crash \\
\hline 1 & Airport & 94 \\
\hline 11 & Koteshwor & 77 \\
\hline 3 & Buspark & 62 \\
\hline 4 & Chabahil & 54 \\
\hline 14 & Singhadurbar & 39 \\
\hline 5 & Durbarmarg & 38 \\
\hline 9 & Kalimati & 32 \\
\hline
\end{tabular}


Percentage Error $(\mathrm{PE})=\frac{\mid \text { Observed Crash-Predicted Crash } \mid}{\text { Observed Crash }} \times 100 \%$
Mean Absolute Deviation(MAD) $=\frac{\sum \mid \text { Observed Crash }- \text { Predicted Crash } \mid}{n}$

Mean Absolute Percentage Error(MAPE $)=\left(\frac{\sum \mid \text { observed Crash-Predicted Crash } \mid}{\text { observed Crash }}\right) / \mathrm{n} \times 100 \%$

Table 7: Testing Parameters for Three Legged Unsignalized Intersections

\begin{tabular}{|c|c|c|c|c|c|c|c|}
\hline $\begin{array}{c}\text { Intersection } \\
\text { ID }\end{array}$ & $\begin{array}{l}\text { Intersection } \\
\text { Name }\end{array}$ & $\begin{array}{l}\text { Predicted } \\
\text { Crash }\end{array}$ & $\begin{array}{l}\text { Observed } \\
\text { Crash }\end{array}$ & $\begin{array}{c}\text { Predicted } \\
\text { Crash- } \\
\text { Observed } \\
\text { Crash }\end{array}$ & $\begin{array}{c}\text { Percentage } \\
\text { Error }\end{array}$ & $\begin{array}{c}\text { Mean } \\
\text { Absolute } \\
\text { Deviation } \\
\text { (MAD) }\end{array}$ & $\begin{array}{c}\text { Mean } \\
\text { Absolute } \\
\text { Percentage } \\
\text { Error } \\
\text { (MAPE) }\end{array}$ \\
\hline 1 & Airport & 94 & 88 & 6 & 6.818 & \multirow{7}{*}{20.571} & \multirow{7}{*}{29.952} \\
\hline 11 & Koteshwor & 77 & 159 & 82 & 51.572 & & \\
\hline 3 & Buspark & 62 & 39 & 23 & 58.974 & & \\
\hline 4 & Chabahil & 54 & 34 & 20 & 58.824 & & \\
\hline 14 & $\begin{array}{c}\text { Singhadurba } \\
\mathrm{r}\end{array}$ & 39 & 36 & 3 & 8.333 & & \\
\hline 5 & Durbarmarg & 38 & 43 & 5 & 11.628 & & \\
\hline 9 & Kalimati & 32 & 37 & 5 & 13.514 & & \\
\hline
\end{tabular}

The difference between predicted crash and observed crash here not only shows that crashes does not solely depend upon the driver's behaviour but may also depend upon other factors like vehicle numbers, presence of heavy vehicles and percentage of motor bikes in the AADT. From the results the countermeasures for the top three ranked intersections can be suggested from the site inspection and crash analysis.

For the calibration of the crash calibration factor a simple regression is carried out and $\mathrm{R}^{2}$ value is calculated which is presented in figure 4 which gives the $\mathrm{R}^{2}$ value of 0.7089 which is acceptable for the regression performed and hence can be concluded that the test of calibration factor has an acceptable value. For the regression analysis Koteshwor Intersection was not considered as the accident rates at this intersection showed alarming fluctuations and affected in the regression analysis. For better improvement of the results in the regression performed, number of intersection can be increased. 


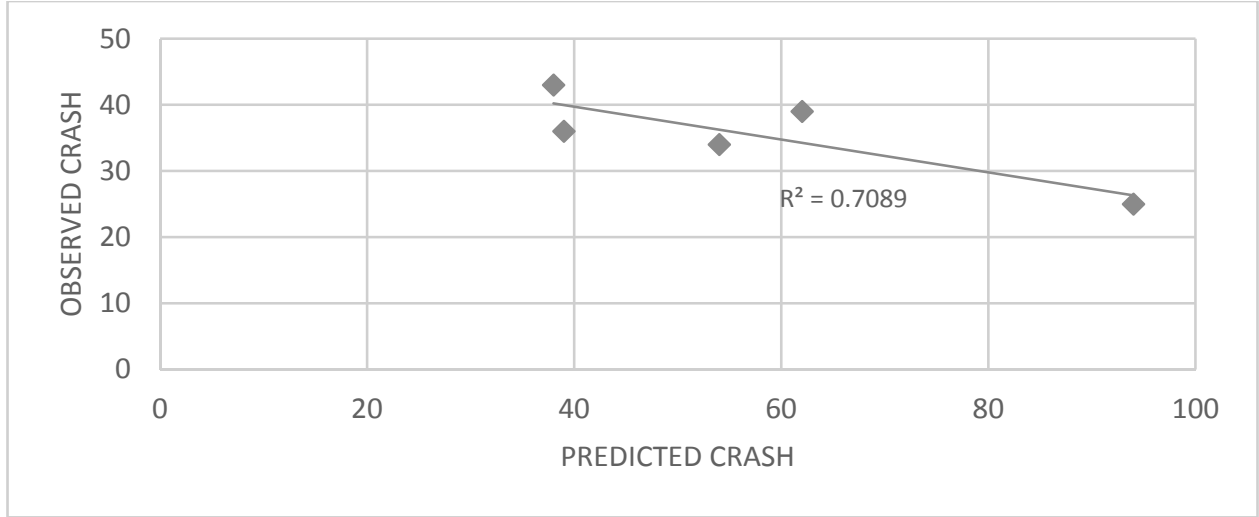

Fig 4: Regression Analysis for Three Legged Unsignalized Intersection

\section{Predicted average crash frequency for NarayangopalChok Intersection}

$\mathrm{N}_{\text {predictedint }}=\quad 2.960$ for calibration coefficient considered 1 as per HSM (AASTHO, 2009).

$$
\begin{aligned}
& C i=\frac{\text { Eobserved Crashes }}{\sum \text { Predicted Crashes }} \\
& C i=\frac{388}{18.201}=21.318
\end{aligned}
$$

Table 8: Ranking of Four Legged Unsignalized Intersection

\begin{tabular}{|r|l|r|}
\hline Intersection ID & Intersection Name & Predicted Crash \\
\hline 12 & NarayangopalChok & 63 \\
\hline 6 & Gaushala & 60 \\
\hline 15 & Swyambhu & 47 \\
\hline 13 & Satdobato & 45 \\
\hline 17 & Kalanki & Thimi \\
\hline 7 & Jawalakhel & 42 \\
\hline 2 & Balkhu & 21 \\
\hline 10 & Kamalpokhari & 20 \\
\hline 16 & Thapathali & 18 \\
\hline
\end{tabular}


Table 9: Testing Parameters for Four Legged Unsignalized Intersections

\begin{tabular}{|c|c|c|c|c|c|c|c|}
\hline $\begin{array}{l}\text { Intersection } \\
\text { ID }\end{array}$ & Intersection Name & $\begin{array}{c}\text { Predicted } \\
\text { Crash }\end{array}$ & $\begin{array}{c}\text { Observed } \\
\text { Crash }\end{array}$ & $\begin{array}{c}\text { Predicted } \\
\text { Crash- } \\
\text { Observed } \\
\text { Crash }\end{array}$ & $\begin{array}{c}\text { Percentage } \\
\text { Error }\end{array}$ & $\begin{array}{c}\text { Mean } \\
\text { Absolute } \\
\text { Deviation } \\
\text { (MAD) }\end{array}$ & $\begin{array}{c}\text { Mean } \\
\text { Absolute } \\
\text { Percentage } \\
\text { Error } \\
\text { (MAPE) }\end{array}$ \\
\hline 12 & Narayangopalchok & 63 & 48 & 15 & 31.250 & \multirow{10}{*}{16.4} & \multirow{10}{*}{39.636} \\
\hline 6 & Gaushala & 60 & 71 & 11 & 15.493 & & \\
\hline 15 & Swyambhu & 47 & 67 & 20 & 29.850 & & \\
\hline 13 & Satdobato & 45 & 51 & 6 & 11.764 & & \\
\hline 8 & Kalanki & 42 & 67 & 25 & 37.313 & & \\
\hline 17 & Thimi & 42 & 67 & 25 & 37.313 & & \\
\hline 16 & Thapathali & 10 & 14 & 4 & 28.570 & & \\
\hline 7 & Jawalakhel & 21 & 37 & 16 & 43.240 & & \\
\hline 2 & Balkhu & 20 & 32 & 12 & 37.500 & & \\
\hline 10 & Kamalpokhari & 18 & 38 & 20 & 52.631 & & \\
\hline
\end{tabular}

For the calibration of the crash calibration factor a simple regression is carried out and $\mathrm{R}^{2}$ value is calculated which is presented in the following figure which gives the $\mathrm{R}^{2}$ value of 0.6275 as shown in figure 5 which is acceptable for the regression performed and hence can be concluded that the test of calibration factor has an acceptable value. For better improvement of the results in the regression performed, number of intersection can be increased.

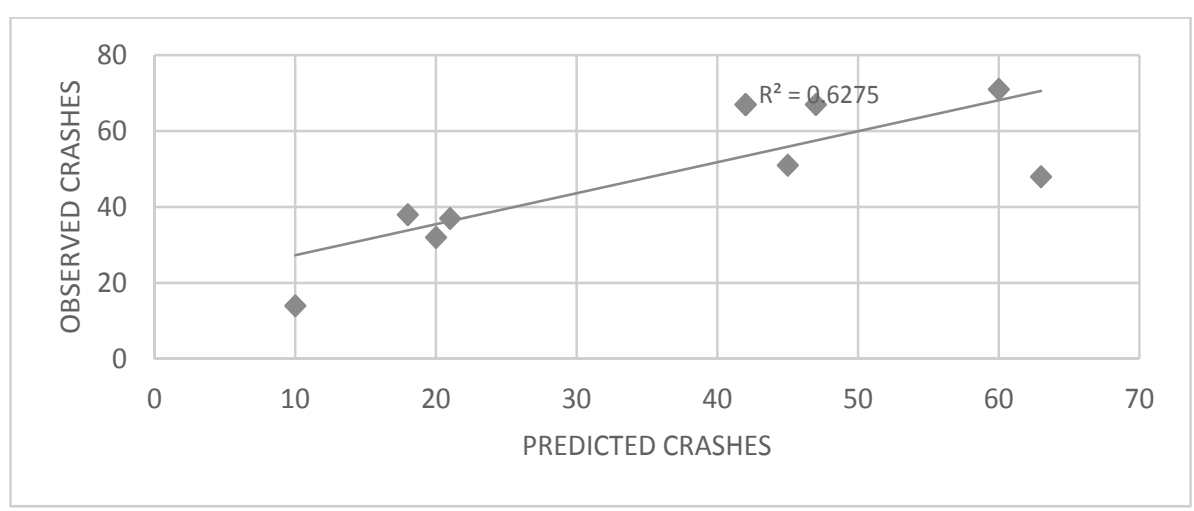

Fig 5: Regression Analysis for Four Legged Unsignalized Intersections

Countermeasures for the top three intersection of both 3ST type and 4ST type intersections are drawn on the basis of results, traffic police suggestions based on their experience and site inspections. Table 10 shows the countermeasures that can be adopted for reduction of crashes at the intersections which have more observed crash than predicted crash. 
Table 10: Countermeasures for Intersections

\begin{tabular}{|l|l|l|l|}
\hline S.N & Intersection Name & Facility Type & Countermeasures \\
\hline 1 & Koteshwor & $3 \mathrm{ST}$ & $\begin{array}{l}\text { Installation of Traffic Signals, } \\
\text { Overhead/Subway Pedestrian Crossings, Clear } \\
\text { Road Markings }\end{array}$ \\
\hline 2 & Durbarmarg & $3 \mathrm{ST}$ & Installation of Traffic Signals \\
\hline 3 & Kalimati & $3 \mathrm{ST}$ & $\begin{array}{l}\text { Installation of Traffic Signals, Enforcement of } \\
\text { No U turn and No Right Turn at intersection }\end{array}$ \\
\hline 4 & Kamalpokhari & $4 \mathrm{ST}$ & Installation of Traffic Signals, Speed Limit \\
\hline 5 & Thimi & $4 \mathrm{ST}$ & Installation of Traffic Signals, Speed Limit \\
\hline 6 & Kalanki & $4 \mathrm{ST}$ & $\begin{array}{l}\text { Installation of Traffic Signals, Overhead } \\
\text { Pedestrian Crossings, Management of Heavy } \\
\text { vehicles, Clear Road Markings }\end{array}$ \\
\hline
\end{tabular}

Education for awareness of all the road users is necessary. Implementation of laws and enforcements should be done effectively to reduce the crashes. Likewise knowledge of road markings to all the road users are necessary. The concerned authorities, DoR, DoTM and MoPIT should start the awareness program from the school level.

\section{Conclusion and Recommendation}

The study was focused on the pattern of accident in Kathmandu valley road network. The analysis of accident shows the trend of accident occurrence in different intersection locations and its surroundings. The minor injury rate is higher than that of seriously injured records. The number of motorbikes involved in the accident in the study locations are significantly high. The fatality of male road user is higher than female. Driver behaviour is the cause of most of the crashes. Technical difficulties in the vehicle, road geometry, road condition, overloading etc. are the other factors of crashes occurring in the location.

Crash occurrence method shows that Koteshwor Intersection is ranked at top among the seventeen intersection selected for the study. Crash rate frequency is another method defined in HSM for ranking of intersection and shows the same intersection (Koteshwor) as top ranked intersection. Critical crash rate value is another method mentioned in HSM for the ranking of intersections. With this method it is found that Kamalpokhari intersection is in the top of the rank. This intersection must be imposed with safety measures for decreasing the critical crash rate.

After the calibration coefficient is found, it was then calibrated using simple Linear Regression model and $\mathrm{R}^{2}$ value was calculated and hence were found within the acceptable range. These intersections are predicted on the basis of HSM which gives the prediction of crashes only with the data available for the facility type describing the geometrics and traffic volume of the intersection only. The traffic control measures, pedestrian behaviour, effect of heavy vehicles are few of many parameters that may lead to crashes and needs to be considered for the prediction of the crashes. 


\section{Recommendations}

The following recommendations can be made from the study performed and conclusions drawn:

* It is recommended to implement the countermeasures suggested to the respective intersections to increase its safety.

* Further research can be done with parameters other than traffic volume and accident frequency.

* It is also recommended to use more number of sites to calibrate the crash coefficient and use in predictive method.

* For the safety assurance of the intersections studied, safety audits can be performed on each intersection by prioritizing the intersection according to the rank to treat the sites as accordingly.

\section{References}

1. AASTHO, 2009. "Highway Safety Manual". s.1.:American Association of State Highway and transportation Officials.

2. Department of Roads, 1997. "Road Safety Note 8", s.1.: Government of Nepal.

3. Ghee, C., Silcock, D., Astrop, A. \& Jacobs, G., 1997. "Socio-economic aspects of road crashes", s.1.: Transport Research Laboratory Report 247:29.

4. Highway Safety Manual, 2009. "Intersection Performance Measure Methods". In: Highway Safety Manual. s.1.:s.n., pp. 27-43.

5. Khanna, S. K. \& Justo, C. E. G., 1990. "Highway Engineering". 7th ed. Roorkee: NEM Chand and Bros.

6. Mehar, R. \& Agrawal, P. K., 2013. "A Systematic Approach for Formulation of a Road Safety Improvement Program in India", s.1.: Science Direct.

7. MTPO, 2016. "Accident Records", Kathmandu: Metropolitan Traffic Police Office.

8. NCHRP, 2003. "A Guide for Addressing Unsignalized Intersection Collision", s.1.: National Cooperative Highway Research Program.

9. Organization for economic Co-operation and Development, 2011. "Road Safety Annual Report", s.l.: Organization for economic Co-operation and Development.

10. Sapkota, N., 2014. "Identification of Accident Prone Zone and Developing and Accident Prediction Model along Naubise-Mugling Section of Prithvi Highway", s.1.: M.Sc. Pulchowk Campus, Tribhuvan University.

11. Shah, D., Varia, H. R. \& Shah, P. M., 2016. "Road Accident Analysis and Severity Prediction Model on State Highway-5" (Halol-Shamlaji Section). International Journal of Scientific Development and Research, 1(5), pp. 346-351.

12. Shanker, R., Chowksey, A. \& Sandhu, H. A. S., 2015. "Analysis of Relationship between Road Safety and Road Design Parameters of Four Lane National Highway in India". Journal of Business and Management, 17(5), pp. 60-70.

13. Thapa, A. J., 2013. "Status Paper on Road Safety in Nepal". s.l., DOR, Department of Road. UN, 2010. The UN Global Action, s.l.: s.n.

14. United Nation, 2011. "Decade of Action For Road Safety" 2011-2020. pp. 4-6.

15. World Health Organization, 2009. "Status Report on Road Safety Time for Action", Geneva: World Health Organization.

16. World Health Organization, 2013. "Global Status Paper on Road Safety", Geneva: World Health Organization (WHO). 